\section{Global health with justice}

Global health law. Lawrence O Gostin. Cambridge, Mass: Harvard University Press, 2014 (560 pp, \$62.88). ISBN 978067478844.

ALTHOUGH the title of Gostin's latest book, Global health law, may suggest a dry legal tome, it is, in fact, a highly readable exploration of the major issues and debates in the field of international health policy and governance. For those new to the field, Gostin offers an insightful overview of the overarching legal and policy regime and key institutional actors. However, the book is not a neutral primer in the basics of health law. Rather, Gostin's ultimate goal is prescriptive: he sets forth in Chapter 1 his vision for "global health with justice" as requiring a more equitable distribution of health resources than the current status quo. In turn, much of the book is devoted to making the case for the political, legal and institutional reform that would be necessary to achieve this end.

"Global health law" is not a clearly defined set of legal instruments - rather, it includes both "hard" law (treaties that are binding on state parties) and "soft" law (non-binding agreements by states). Given this complex legal landscape, as well as the fact that much of the relevant legal architecture does not specify concrete obligations for state parties, Gostin takes a more expansive approach to the field. He examines not only international legal frameworks and relevant agreements, but also good governance

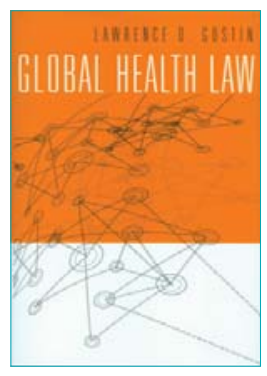

practices for key institutions, such as the World Health Organization, as well as diverse stakeholders in philanthropy, business and civil society.

Gostin covers a great deal of ground - from the lack of political will at the $\mathrm{WHO}$, to human rights, and the impact of the current international trade and intellectual property regimes on health outcomes. He concludes with a series of case studies on a diverse set of health problems. While this approach inherently eschews a certain degree of depth on a number of issues, it is valuable in that it provides readers with a comprehensive understanding of the multiple intersecting factors - social, legal, political and economic - that shape international health policies and processes.

Ultimately, Gostin's case for an urgent need for global health with justice is compelling. The final chapter highlights the opportunity for advocates and policymakers to capitalise on current international attention on health to push forward two new initiatives: a proposal for a binding international "Framework convention on global health"; and a multilateral treaty to incentivise research and development based on universal need rather than profit. If successful, either would be a major step forward in strengthening the global health legal framework. 